\title{
A novel nomogram for the treatment of astigmatism with femtosecond-laser arcuate incisions at the time of cataract surgery
}

This article was published in the following Dove Press journal:

Clinical Ophthalmology

13 October 2017

Number of times this article has been viewed

\section{Connor J Baharozian' \\ Christian Song ${ }^{2,3}$ \\ Kathryn M Hatch ${ }^{2,3}$ \\ Jonathan H Talamo ${ }^{2,3}$}

'Boston University School of Medicine, ${ }^{2}$ Massachusetts Eye and Ear Infirmary, ${ }^{3}$ Department of Ophthalmology, Harvard Medical School, Boston, MA, USA
Correspondence: Jonathan H Talamo Massachusetts Eye and Ear Infirmary, I60| Trapelo Road, Suite 184, Waltham, MA 0245I, USA

Tel + I 78I 8901023

$\mathrm{Fax}+$ I 7818902507

Email jonathan_talamo@meei.harvard.edu
Purpose: The purpose of this study was to determine an arcuate incision (AI) nomogram to treat astigmatism during femtosecond laser-assisted cataract surgery.

Methods: This is a retrospective, cohort study. Femtosecond laser (FSL)-assisted transepithelial AIs were created at a $9.0 \mathrm{~mm}$ optical zone, $80 \%$ depth, centered on the limbus. We modified the manual Donnenfeld limbal relaxing incision nomogram to $70 \%$ for with-the-rule (WTR), $80 \%$ for oblique (OBL), and 100\% for against-the-rule (ATR) astigmatism. The correction index (CI) equaled AI-induced astigmatism/target-induced astigmatism. Measures included preoperative keratometric corneal cylinder (Pre Kcyl), postoperative Kcyl (Post Kcyl), and postoperative residual refractive astigmatism (Post RRA).

Results: Mean Pre Kcyl and 1-2 months Post RRA in 161 eyes of 116 patients were $0.626 \pm 0.417$ diopters (D) (range 0.5-2 D), and 0.495 $\pm 0.400 \mathrm{D}$ (range 0-1.5 D), respectively. Mean absolute astigmatic changes (Pre Kcyl-Post Kcyl) without accounting for axis change in the WTR, ATR, and OBL groups were $0.165 \pm 0.383 \mathrm{D}(P<0.001), 0.374 \pm 0.536 \mathrm{D}$ $(P<0.001)$, and $0.253 \pm 0.416 \mathrm{D}(P=0.02)$, respectively. Mean absolute astigmatic changes using RRA as the postoperative measurement (Pre Kcyl-Post RRA) without accounting for axis change were $0.440 \pm 0.461 \mathrm{D}(P<0.001), 0.238 \pm 0.571 \mathrm{D}(P<0.05), 0.154 \pm 0.450(P=0.111)$ in WTR, ATR, and OBL groups, respectively. CIs for WTR, ATR, and OBL were 0.53, 1.01, and 0.95, respectively. There were no intraoperative or postoperative complications related to the AIs.

Conclusion: Transepithelial FSL-AIs using the modified Donnenfeld nomogram show potential for management of mild to moderate corneal astigmatism. An increase in the magnitude or reduction of the optical zone size for the treatment of WTR and ATR astigmatism for this nomogram may further improve refractive accuracy.

Keywords: femtosecond laser, cataract surgery, astigmatism, keratotomy, nomogram, limbal relaxing incisions

\section{Introduction}

Recent large-scale retrospective surveys report that about three-quarters of patients preparing for cataract surgery have corneal astigmatism $\geq 0.5$ diopters (D). ${ }^{1,2}$ Precise management of astigmatism is critical to achieve excellent uncorrected visual acuity outcomes. Degradation of visual quality occurs when refractive astigmatism $\geq 0.5 \mathrm{D}$ is present. ${ }^{3}$ While it is possible for some patients to achieve excellent unaided visual acuity with as much as $1 \mathrm{D}$ of residual refractive astigmatism (RRA) following cataract surgery with a monofocal lens implant, ${ }^{4}$ eyes receiving multifocal or extended depth of focus lens implants with diffractive optics are less forgiving and may be affected by as little as $0.5 \mathrm{D}$ of RRA. ${ }^{4-6}$ 
Reduction of corneal astigmatism by means of carefully placed manual limbal relaxing incisions (LRIs) has a long track record of good efficacy, safety, and predictability. ${ }^{7,8}$ Modifications in the length, depth, optical zone, and number of incisions influence the amount of correction achieved with a given incision. ${ }^{9-12}$ Nomograms, by factoring in the effect of several of these parameters, facilitate surgical planning by simplifying an otherwise complex process of determining the proper treatment for an intended correction.

The introduction of femtosecond laser-assisted cataract surgery (FLACS) has provided renewed impetus to further refine the precision and accuracy of cataract surgical techniques. The use of the image-guided femtosecond laser (FSL) to treat low-to-moderate corneal astigmatism ( $\leq 2 \mathrm{D})$ with arcuate incisions (AIs) has been reported in post-keratoplasty, pseudophakic, and naive eyes. ${ }^{11-18}$

Existing nomograms for manual LRIs are widely accessible ${ }^{19-23}$ and, when done with a proper and reproducible technique, are accurate and precise. We report results using a modification of the Donnenfeld LRI nomogram for the creation of transepithelial AIs at the time of FLACS to treat low-to-moderate amounts of astigmatism. Given the increasing use of FLACS, a reproducible nomogram for the creation of AIs would be useful for refractive cataract surgeons.

\section{Patients and methods}

As this was a large retrospective study, a waiver of informed consent and a Health Insurance Portability and Accountability Act waiver were reviewed and approved by Quorum Review Institutional Review Board (Quorum, Olympia, WA, USA). The study followed the tenets of the Declaration of Helsinki. In this retrospective cohort study, we reviewed the charts of consecutive patients who underwent FLACS and FSL-created transepithelial AIs by two surgeons (KMH and JHT) at a single ambulatory surgical center over a period of 30 months (December 2012 to May 2015). All patients were informed of the risks and benefits of, as well as alternatives to, the proposed surgery and provided written consent for surgery in accordance with institutional guidelines.

All included subjects had a cataract, deemed visually significant by the surgeon and corneal astigmatism measuring $0.25 \mathrm{D}$ to $2.0 \mathrm{D}$ with expected potential visual acuity of at least 20/25 as determined by preoperative clinical evaluation and history. Contact lens wearers and eyes with prior corneal surgeries, corneal endothelial disease (eg, Fuch's dystrophy), conditions causing irregular astigmatism (eg, corneal ectatic disorders), extreme myopia exceeding $-18.00 \mathrm{D}$ spherical equivalent (SE), or hyperopia exceeding +7.00 D SE were excluded from the study. Eyes with a history of intraocular surgery (eg, vitrectomy) or coexisting pathology deemed to either limit postoperative visual acuity (eg, epiretinal membrane) or increase the risk of intraoperative complications (eg, pseudoexfoliation) were also excluded.

FSL pretreatments of the lens and corneal transepithelial (anterior penetrating without opening) AIs were performed with the Catalys femtosecond laser platform (Johnson \& Johnson Vision, Santa Ana, CA, USA) in all cases. Cataract extraction was completed by phacoemulsification using either the Infiniti or Centurion systems (Alcon Laboratories, Inc., Fort Worth, TX, USA).

\section{Preoperative surgical planning}

Preoperative evaluation and planning consisted of slit-lamp biomicroscopy, dilated fundoscopy, optical biometry (IOL Master V5.4; Carl Zeiss Meditec AG, Jena, Germany) and corneal topographic analysis (ATLAS 9000; Carl Zeiss Meditec AG).

Intraocular lens (IOL) power calculations were performed with the IOL Master using the SRK/T and Hoffer-Q formulas for axial lengths $\geq 22$ and $<22 \mathrm{~mm}$, respectively. Incision size and surgically induced astigmatism (SIA) values were determined by the individual surgeon. Depending on the incision size, location, and surgeon factor selected, the SIA ranged from $0.25 \mathrm{D}$ to $0.5 \mathrm{D}$.

We defined with-the-rule (WTR), against-the-rule (ATR), and oblique (OBL) astigmatism as the steep corneal cylinder meridian oriented at $90^{\circ} \pm 30^{\circ}, 180^{\circ} \pm 30^{\circ}$, and $45^{\circ} \pm 14^{\circ}$ or $135^{\circ} \pm 14^{\circ}$, respectively, as determined by preoperative keratometry (ATLAS 9000). We modified the Donnenfeld nomogram to account for the contribution of posterior corneal astigmatism, which adds to ATR while it subtracts from WTR astigmatism. ${ }^{24,25} \mathrm{We}$ used $70 \%$ of the suggested treatment for WTR, $80 \%$ for OBL, and 100\% for ATR astigmatism (Table 1). The derivation of these adjustment factors is reviewed in the "Discussion" section.

Table I Modification of Donnenfeld nomogram

\begin{tabular}{lll}
\hline Axis orientation & $\begin{array}{l}\text { Degrees of } \\
\text { astigmatism }\end{array}$ & $\begin{array}{l}\text { Percentage of } \\
\text { Donnenfeld nomogram }\end{array}$ \\
\hline With-the-rule & $60-120$ & 70 \\
Against-the-rule & $0-30$ and & 100 \\
& $150-180$ & \\
Oblique & $31-59$ and & 80 \\
& $121-149$ & \\
\hline
\end{tabular}




\section{Surgical technique and laser parameters}

Standard preoperative topical medications including phenylephrine $2.5 \%$, tropicamide $1 \%$, and proparacaine $0.5 \%$ were administered. With the patient sitting upright, a 3-pronged reference marker was used to mark the limbus at 3,6, and 9 o'clock. After positioning and docking the patient's eye underneath the laser apparatus, proper orientation and correction for cyclotorsion were ensured by adjusting on-screen guidelines with the preplaced marks on the eye displayed in a live infrared image. Guided by realtime spectral domain optical coherence tomography, all AIs were placed at a $9.0 \mathrm{~mm}$ optical zone, centered on the limbus, and created as anterior penetrating incisions orthogonal to the anterior corneal surface and extending to $80 \%$ of total corneal depth (Figure 1). These AIs were not intentionally opened, manipulated, or adjusted concurrent or subsequent to their creation.
Paired AIs were created for WTR and OBL astigmatism. For ATR treatments, a single AI was created nasally on the axis opposite the manually created temporal clear corneal incision (CCI), which was placed on the steep axis whenever possible as dictated by the surgeon's desired hand position.

After completion of the FSL pretreatment, the patient was transferred to the operating room for phacoemulsification (Catalys system) with monofocal intraocular lens implantation under a sterile field. The temporal CCI was constructed manually with a keratome blade at the limbus in a tri-planar configuration. All patients were placed on a postoperative regimen of eye drop medications that included a topical corticosteroid, fluoroquinolone antibiotic, and nonsteroidal anti-inflammatory drug. Refraction, automated keratometry (OPD-Scan III; Nidek Co, Ltd, Gamagori, Aichi, Japan) and corneal topography (Atlas 9000) were obtained at 1- to 2-month postoperative visit.
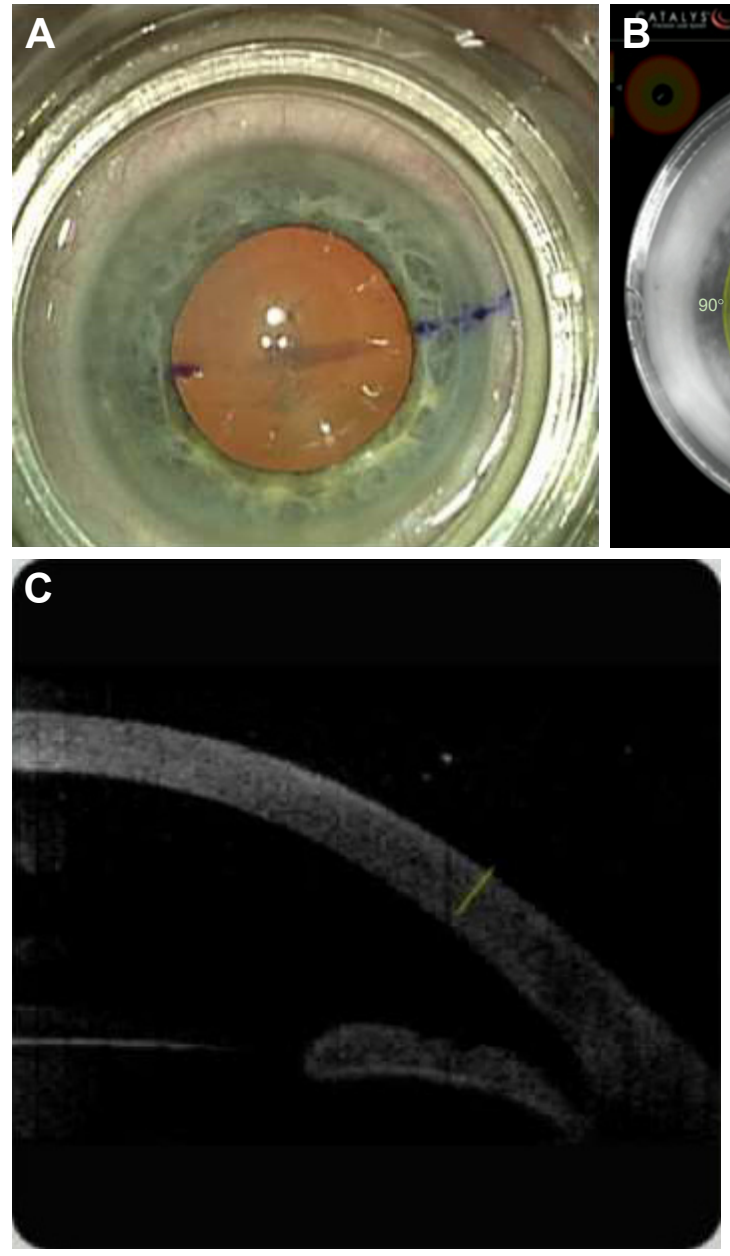

Figure I Basic procedure: place incisions, (A) align suction ring, (B) set parameters, (C and D) confirm 3D depth with optical coherence tomography
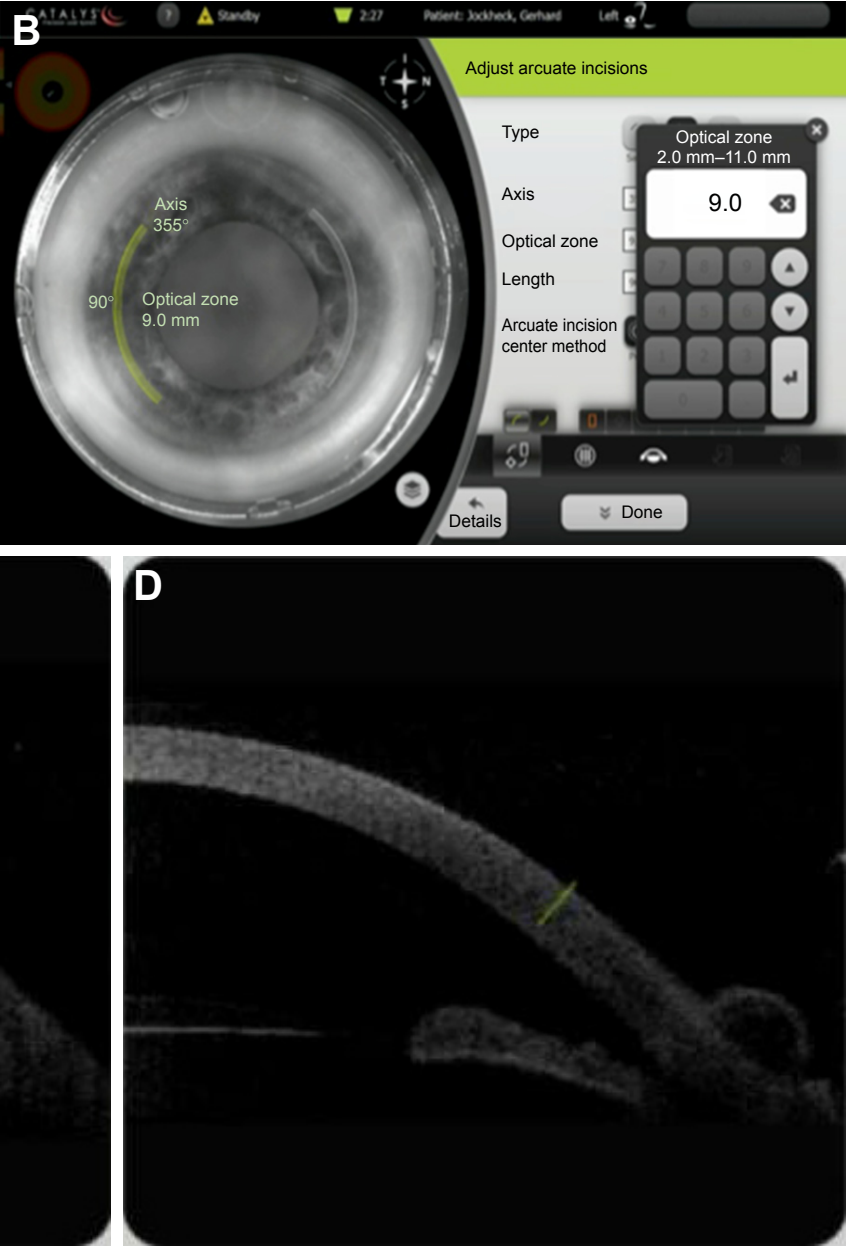
Table 2 Preoperative Kcyl, postoperative Kcyl, and postoperative RRA (in diopters)

\begin{tabular}{|c|c|c|c|c|}
\hline Measures & $\begin{array}{l}\text { WTR astigmatism } \\
(\mathrm{n}=104) \\
\text { Mean } \pm \text { SD (range) }\end{array}$ & $\begin{array}{l}\text { ATR astigmatism } \\
(n=43) \\
\text { Mean } \pm \text { SD (range) }\end{array}$ & $\begin{array}{l}\text { OBL astigmatism } \\
(n=14) \\
\text { Mean } \pm \text { SD (range) }\end{array}$ & $\begin{array}{l}\text { All eyes }(n=161) \\
\text { Mean } \pm \text { SD (range) }\end{array}$ \\
\hline Preoperative Kcyl & $0.829 \pm 0.3 \mid 4(0.5-2.0)$ & $0.947 \pm 0.302(0.5-1.75)$ & $0.779 \pm 0.360(0.5-1.9)$ & $0.856 \pm 0.3 \mid 8(0.5-2.0)$ \\
\hline Postoperative Kcyl & $0.664 \pm 0.397(0.0-1.5)$ & $0.573 \pm 0.486(0.0-2.00)$ & $0.526 \pm 0.303(0.0-1.0)$ & $0.626 \pm 0.417(0.0-2.0)$ \\
\hline Postoperative & $0.389 \pm 0.328(0.0-1.25)$ & $0.709 \pm 0.475(0.0-1.75)$ & $0.689 \pm 0.446(0.0-2.25)$ & $0.495 \pm 0.400(0-1.5)$ \\
\hline \multicolumn{5}{|l|}{ RRA } \\
\hline Mean $\Delta \mathrm{Kcyl}$ & $0.165 \pm 0.383(-0.55-1.5)$ & $0.374 \pm 0.536(-0.85-1.5)$ & $0.253 \pm 0.416(-0.45-1.15)$ & $0.230 \pm 0.436(-0.85-1.5)$ \\
\hline$P$-values of $\Delta \mathrm{Kcyl}$ & $<0.001$ & $<0.001$ & 0.02 & $<0.001$ \\
\hline
\end{tabular}

Note: Mean $\Delta \mathrm{Kcyl}=$ preoperative $\mathrm{Kcyl}$-postoperative Kcyl.

Abbreviations: Kcyl, keratometric corneal cylinder; RRA, residual refractive astigmatism; WTR, with-the-rule; ATR, against-the-rule; OBL, oblique.

\section{Data analysis}

The primary outcome measure was the change from preoperative to postoperative keratometric corneal cylinder (Kcyl), evaluated between 30 and 60 days after surgery. Secondary endpoints included mean RRA, responder analyses examining the percentage of eyes with $<0.5 \mathrm{D}$ Kcyl or 0.5 D RRA and the ASSORT correction index (CI) during the same time frame. Vector analysis was performed, utilizing the Alpins vector method, with ASSORT software (ASSORT Pty; Cheltenham, Victoria, Australia) to evaluate both the magnitude and directionality of the astigmatic effect. ${ }^{26}$ Target induced astigmatism (TIA), calculated by ASSORT, was the intended astigmatism correction vector. ASSORT used preoperative Kcyl and our ideal, calculated incisions (www.lricalculator.com) to complete this calculation. The actual amount and axis of astigmatic effect achieved defined the AI-induced astigmatism (AIIA) vector. This was again determined by ASSORT using the change in preoperative Kcyl to postoperative Kcyl. Finally, ASSORT calculated a CI, a ratio of AIIA to TIA, as a measure of treatment accuracy and indication of overcorrection $(\mathrm{CI}>1)$ or under correction $(\mathrm{CI}<1)$. A secondary analysis was performed using RRA as a surrogate for postoperative Kcyl to analyze the treatment effect on total astigmatism. A paired $t$-test was used to compare continuous variables. Probabilities of $<5 \%$ were considered significant $(P<0.05)$.

\section{Results}

The study included 161 eyes of 116 patients with a mean age of $67 \pm 10$ years (range $30-86$ years). Postoperative follow-up ranged from 30 to 60 days. Subjects were subdivided into WTR, ATR, and OBL astigmatic groups, consisting of 106, 43, and 14 eyes, respectively. The mean difference between preoperative and postoperative Kcyl for all eyes was $0.230 \pm 0.436 \mathrm{D}$, representing a statistically significant reduction of astigmatism $(P<0.001)$. Table 2 displays the mean preoperative and postoperative Kcyl for each astigmatism group and all eyes together.

The proportion of eyes achieving $\leq 0.5 \mathrm{D}$ Kcyl preoperative and postoperative are shown in Figure 2. Figure 3 shows the CI results of the Alpins vector analysis for each group. The mean correction indices were $0.53,1.01$, and 0.95 in the WTR, ATR, and OBL groups, respectively. These values suggest that the treatment resulted in mild undercorrection overall. Overcorrection of $>50 \%$ was observed most frequently in the ATR group, occurring in 8 eyes (18.6\%) (Table 3).

The CI vector plots show the magnitude of induced astigmatism relative to the TIA, in addition to its axis. Thus, the axis of the induced astigmatism and, consequently, each vector should theoretically lie $90^{\circ}$ away from the steep axis. As illustrated in Figure 3, the vectors are generally oriented horizontally $\left(0^{\circ}-30^{\circ}\right.$ and $\left.150^{\circ}-180^{\circ}\right)$ for WTR, vertically $\left(60^{\circ}-120^{\circ}\right)$ for ATR, and in the intervening areas $\left(31^{\circ}-59^{\circ}\right.$ and $121^{\circ}-149^{\circ}$ ) for OBL.

No intraoperative or postoperative complications, including perforation, wound gape, infection, or lens malposition, occurred in any patient.

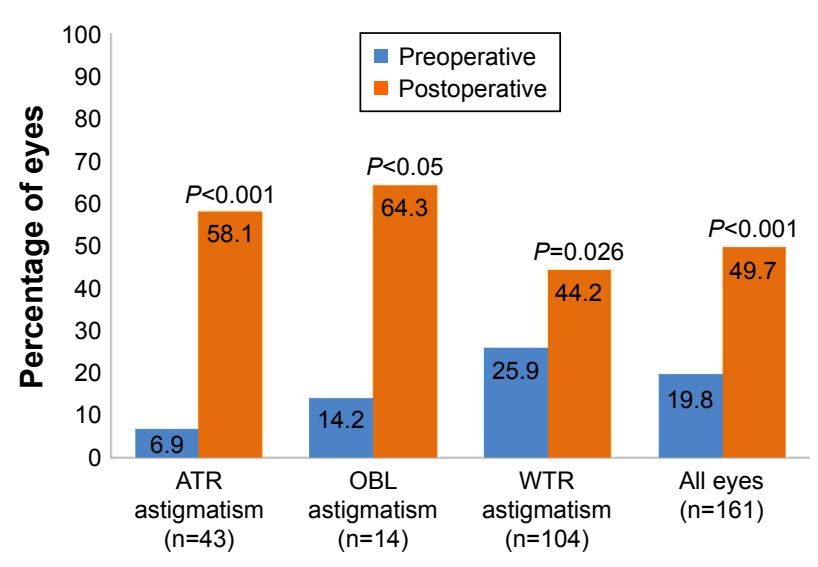

Figure 2 Percentage of eyes with $\leq 0.5$ diopters of keratometric cylinder preoperative and postoperative in eyes with against-the-rule, oblique, and with-therule astigmatism, and all astigmatic eyes combined.

Abbreviations: ATR, against-the-rule; OBL, oblique; WTR, with-the-rule. 

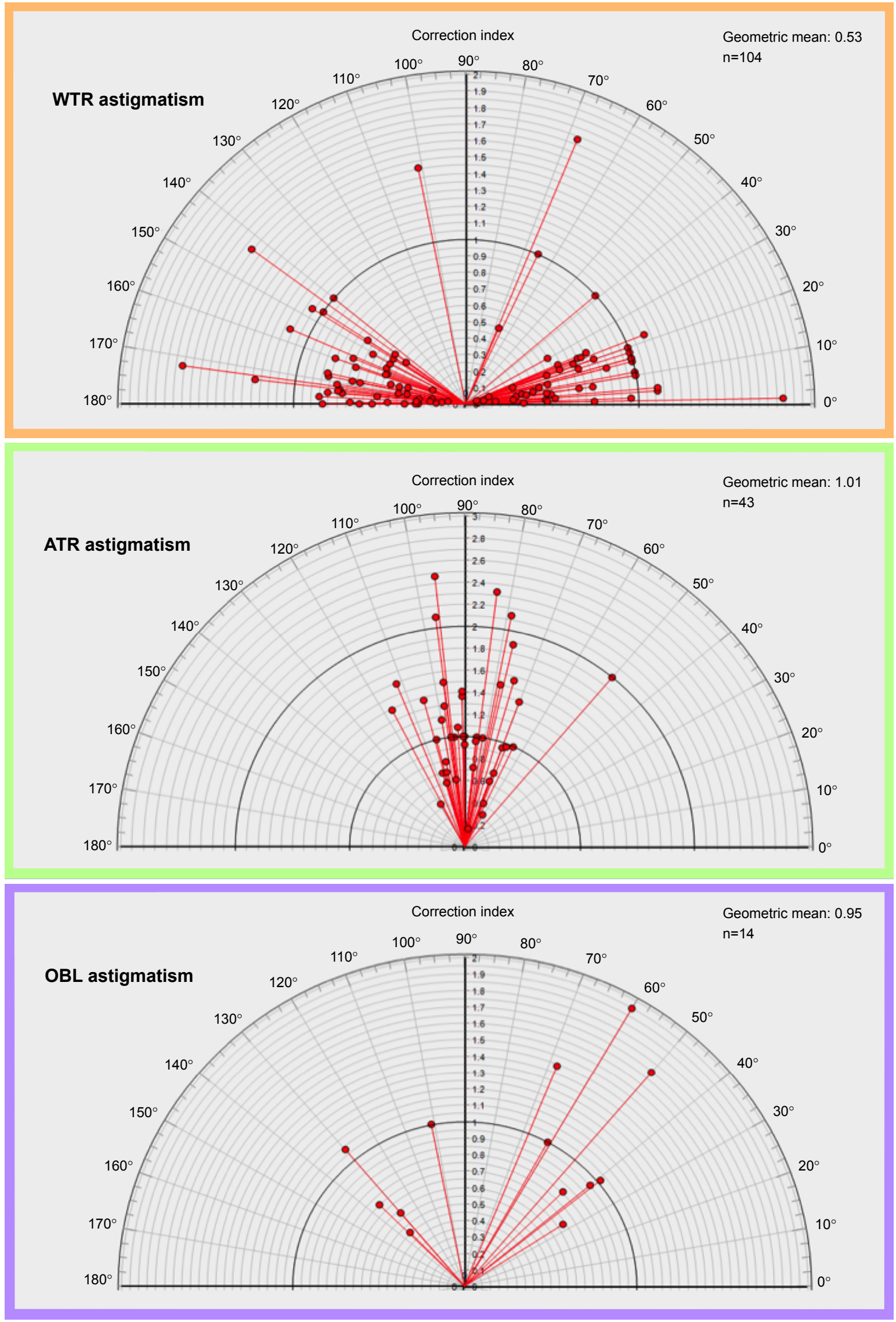

Figure 3 Correction index vector plots, preoperative Kcyl and postoperative Kcyl.

Abbreviations: Kcyl, keratometric corneal cylinder; WTR, with-the-rule; ATR, against-the-rule; OBL, oblique. 
Table 3 Distribution of overcorrected eyes after femtosecondassisted arcuate incisions

\begin{tabular}{|c|c|c|c|c|c|c|}
\hline \multirow{2}{*}{$\begin{array}{l}\text { Axis } \\
\text { orientation }\end{array}$} & \multicolumn{2}{|l|}{$>150 \%$} & \multicolumn{2}{|l|}{$>125 \%$} & \multicolumn{2}{|l|}{$>100 \%$} \\
\hline & Kcyl & RRA & Kcyl & RRA & Kcyl & RRA \\
\hline $\begin{array}{l}\text { VTR } \\
\text { stigmatism }\end{array}$ & $\begin{array}{l}2.8 \% \\
(3 / 104)\end{array}$ & $\begin{array}{l}9.6 \% \\
(10 / 104)\end{array}$ & $\begin{array}{l}4.8 \% \\
(5 / 104)\end{array}$ & $\begin{array}{l}16.3 \% \\
(17 / 104)\end{array}$ & $\begin{array}{l}10.6 \% \\
(11 / 104)\end{array}$ & $\begin{array}{l}24.0 \% \\
(25 / 104)\end{array}$ \\
\hline $\begin{array}{l}\text { TR } \\
\text { stigmatism }\end{array}$ & $\begin{array}{l}18.6 \% \\
(8 / 43)\end{array}$ & $\begin{array}{l}2.3 \% \\
(1 / 43)\end{array}$ & $\begin{array}{l}37.2 \% \\
(16 / 43)\end{array}$ & $\begin{array}{l}13.9 \% \\
(6 / 43)\end{array}$ & $\begin{array}{l}41.8 \% \\
(19 / 43)\end{array}$ & $\begin{array}{l}25.5 \% \\
(11 / 43)\end{array}$ \\
\hline $\begin{array}{l}\text { OBL } \\
\text { astigmatism }\end{array}$ & $\begin{array}{l}14.2 \% \\
(2 / 14)\end{array}$ & $\begin{array}{l}7.1 \% \\
(1 / 14)\end{array}$ & $\begin{array}{l}21.4 \% \\
(3 / 14)\end{array}$ & $\begin{array}{l}14.2 \% \\
(2 / 14)\end{array}$ & $\begin{array}{l}35.7 \% \\
(5 / 14)\end{array}$ & $\begin{array}{l}14.2 \% \\
(2 / 14)\end{array}$ \\
\hline
\end{tabular}

Abbreviations: Kcyl, keratometric corneal cylinder; RRA, residual refractive astigmatism; WTR, with-the-rule; ATR, against-the-rule; OBL, oblique.

\section{Discussion}

Residual astigmatism is a common cause of increased spectacle dependence and patient dissatisfaction after cataract surgery. A statistically significant decrease in Kcyl was demonstrated in all eyes after AIs based on our modification of the Donnenfeld nomogram for low amounts of corneal astigmatism. In the current study, $49.7 \%$ of eyes achieved a postoperative Kcyl of $\leq 0.5 \mathrm{D}$. This result was most commonly observed for the OBL group (64.3\%), followed by the ATR (56.1\%) and WTR groups (44.2\%). However, this change did not reach statistical significance for the OBL group, possibly due to the small sample size. As shown (Table 2), mean WTR reduction was $<0.25 \mathrm{D}$, the cutoff value for what is commonly considered clinically significant. This can be explained by the disproportionate number of patients in the WTR cohort with lower amounts of preoperative Kcyl ( $87 \%$ had $<1 \mathrm{D})$, along with the fact that eyes with WTR astigmatism received less treatment as a percentage of the Donnenfeld nomogram when compared to eyes in the OBL or ATR groups. This was done so as not to risk overcorrection given that posterior corneal astigmatism is most common in the ATR direction.

Several nomograms for manually constructed LRIs exist. ${ }^{19-23}$ However, very little has been reported regarding the applicability of these nomograms to FSL-assisted AIs. Chan et $\mathrm{al}^{16}$ recently reported on a series of 54 eyes treated with a single FSL-assisted AI paired with the main cornea incision during cataract surgery using a modified form of the Wallace Limbal Relaxing Incision Nomogram. In this study, $33 \%$ of eyes had postoperative astigmatism of $\leq 0.5 \mathrm{D}$. They reasoned that a small increase in the treatment nomogram, derived from the coefficient of adjustment (the inverse of the mean CI), could have improved their results. More recently, Day et al published the results on the efficacy of FSL, intrastromal, astigmatic keratotomy using a personalized nomogram in which they achieved a mean astigmatic reduction of $63 \% .{ }^{18}$ The percentage of eyes attaining $\leq 1.0 \mathrm{D}$ and $\leq 0.50 \mathrm{D}$ corneal cylinder in their series was $85.7 \%$ and $32.1 \%$, respectively. Intrastromal incisions, a unique capability of the FSL, have the potential to eliminate the risk of infection and reduce postoperative discomfort. However, the drawbacks of this approach include the need for a smaller optical zone and that inadvertent anterior perforation of intrastromal AIs can lead to significant astigmatic overcorrection. In addition, some surgeons may prefer having the option to further titrate astigmatic effect postoperatively by opening or re-opening AIs anteriorly. This is easily accomplished for transepithelial AIs but is not feasible for intrastromal AIs. While our patient population may not have been identical to that in the study by Day et al, making comparisons difficult, our nomogram and adjustment factors for transepithelial AIs resulted in $49.7 \%$ of eyes with postoperative astigmatism of $\leq 0.5 \mathrm{D}$.

The adjustment factors applied for each astigmatism group in our study were intended to avoid overcorrections by taking into account the following two important factors: 1) the smaller $9.0 \mathrm{~mm}$ optical zone (as compared to manual LRIs on which the Donnenfeld nomogram is based) that could modestly increase the effect of a given incision; 2) the small, but appreciable, effect on total corneal astigmatism by the posterior corneal surface as reported by Koch et al, which disclosed a tendency of the posterior cornea to induce, on average, $0.3 \mathrm{D}$ of ATR astigmatism in a cataract surgery population study cohort. ${ }^{24}$

In addition to Kcyl data, postoperative RRA was also measured. While Kcyl measures anterior corneal astigmatism, RRA reflects the influence of posterior corneal astigmatism in addition to what was measured by keratometry. As such, RRA provides a more meaningful metric of the total amount of astigmatism influencing patient visual acuity. When comparing RRA to Kcyl postoperative data, a greater proportion of subjects have $\leq 0.5 \mathrm{D}$ of astigmatism in the RRA group (63.4\% compared to $49.7 \%$ ). While the changes in Kcyl observed for the patient cohort analyzed here are modest, the RRA analysis suggests that the influence of laser AIs on visual outcomes using the nomogram approach studied herein are better than what Kcyl postoperative data suggests.

In our study, the mean CIs in the WTR, ATR, and OBL groups were $0.53,1.01$, and 0.95 , respectively. A perfect treatment in which the AIIA is equivalent to TIA would result in a CI of 1 . These values suggest that systematic overcorrection was largely avoided, but occurred most frequently in 
the ATR group ( $18.6 \%$ with $>150 \%$ of intended correction $)$. A CI of 1.01 in the ATR group suggests that astigmatism was neutralized as intended. However, when taking RRA in place of postoperative Kcyl for the calculation of CI, the CI becomes 0.75 , and overcorrections of $>150 \%$ decrease to just $2.3 \%$ (Table 3 ). We presume that additional posterior corneal ATR astigmatism not detected by traditional keratometry largely accounts for this difference. ${ }^{24,25}$ Results of WTR treatments using Kcyl data suggest that there was systematic undercorrection $(\mathrm{CI}=0.53)$. On a practical level, modest undercorrection with WTR astigmatism may be considered acceptable and, in fact, desired to compensate for the aging eye and contribution of the posterior cornea. ${ }^{24}$

This study involved astigmatic corrections of fairly low magnitudes. Caution must be exercised when interpreting CIs for lower astigmatic treatments. A recent analysis by Bullimore et $\mathrm{a}^{27}$ demonstrated that inherent variability in the measurement of astigmatism can be expected to result in CIs $<1$ when the magnitude of TIA is close to the measurement variability. Thus, proper interpretation of the individual cases in which the CI was $>1$ in the current study may be affected by this intrinsic error.

The FSL-AIs in this study were not intentionally opened following their creation. This may have introduced some variability in the outcomes as some incisions may have opened spontaneously while others did not. More effect could have been observed, if all the incisions were opened in the operating room or subsequently in the clinic.

Incision size was standardized for each surgeon in the study, and each surgeon used their own SIA values in calculating astigmatic outcomes, possibly affecting the study outcome. The short follow-up period of 30-60 days may be an additional limitation to this study. Manual arcuate keratotomy incisions with an optical zone of $7.0 \mathrm{~mm}$ have an effect that correlates well with 1 -year results, ${ }^{28}$ though whether this holds true for FSL-AIs and an optical zone of $9.0 \mathrm{~mm}$ is not well established. In postkeratoplasty eyes, the maximum effect of FSL-assisted arcuate keratotomy occurred at 6 weeks, followed by mild regression and stabilization by 3 months. ${ }^{29}$ Longer follow-up data may be necessary to better ascertain the treatment effect.

Our results suggest a method for planning transepithelial AIs created by an image-guided FSL; this approach is based on an adaptation of the Donnenfeld nomogram and is useful for correcting keratometric astigmatism of $\leq 1.25 \mathrm{D}$. Caution should be used if considering this approach with a different brand of FS laser, as actual optical zone size and incision depth may vary even if the same parameters are used to program the laser. It is likely that the percentage of eyes achieving $0.5 \mathrm{D}$ or less RRA could be increased by using a more aggressive nomogram (larger percentage of Donnenfeld calculation and/or a smaller optical zone size). For example, an increase to an $85 \%$ adjustment factor with the Donnenfeld nomogram for WTR astigmatism may reduce the CI; however, the proportion of overcorrections would likely also increase. While this may be well tolerated when the absolute amount of astigmatism is small (ie, $\leq 1 \mathrm{D}$ ), some patients are quite sensitive to a flipped axis, especially if it only occurs in one eye. As such, it may be appropriate to slightly undercorrect WTR cylinder as well as treat (or even slightly overcorrect) all ATR cylinder due to the contribution of posterior cornea and the gradual shift toward increased ATR astigmatism that may occur over time. Future studies should allow for refinement of the nomogram as well as determine the influence of manually enhancing the effect of FSL-AI by opening the incisions.

\section{Disclosure}

The authors report no conflicts of interest in this work.

\section{References}

1. Khan MI, Muhtaseb M. Prevalence of corneal astigmatism in patients having routine cataract surgery at a teaching hospital in the United Kingdom. J Cataract Refract Surg. 2011;37(10):1751-1755.

2. Yuan X, Song H, Peng G, Hua X, Tang X. Prevalence of corneal astigmatism in patients before cataract surgery in northern China J Ophthalmol. 2014;2014:536412. Available from: http://www.hindawi. com/journals/joph/2014/536412/. Accessed May 25, 2016.

3. Villegas EA, Alcon E, Artal P. Minimum amount of astigmatism that should be corrected. J Cataract Refract Surg. 2014;40(1):13-19.

4. Amesbury EC, Miller KM. Correction of astigmatism at the time of cataract surgery. Curr Opin Ophthalmol. 2009;20(1):19-24.

5. Hayashi K, Hayashi H, Nakao F, Hayashi F. Influence of astigmatism on multifocal and monofocal intraocular lenses. Am J Ophthalmol. 2000;130:477-482.

6. de Vries NE, Webers CA, Touwslager WR, et al. Dissatisfaction after implantation of multifocal intraocular lenses. J Cataract Refract Surg. 2011;37(5):859-865.

7. Budak K, Friedman NJ, Koch DD. Limbal relaxing incisions with cataract surgery. J Cataract Refract Surg. 1998;24(4):503-508.

8. Nichamin LD. Treating astigmatism at the time of cataract surgery. Curr Opin Ophthalmol. 2003;14(1):35-38.

9. Price FW, Grene RB, Marks RG, Gonzales JS. Astigmatism reduction clinical trial: a multicenter prospective evaluation of the predictability of arcuate keratotomy. Evaluation of surgical nomogram predictability. ARC-T study group. Arch Ophthalmol. 1995;113(5):277-282.

10. Muller-Jensen K, Fischer P, Siepe U. Limbal relaxing incisions to correct astigmatism in clear corneal cataract surgery. $J$ Refract Surg. 1999;15(5):586-589.

11. Harissi-Dagher M, Azar DT. Femtosecond laser astigmatic keratotomy for postkeratoplasty astigmatism. Can J Ophthalmol. 2008;43(3) 367-369.

12. Nubile M, Carpineto P, Lanzini M, et al. Femtosecond laser arcuate keratotomy for the correction of high astigmatism after keratoplasty. Ophthalmology. 2009;116(6):1083-1092. 
13. Wetterstrand O, Holopainen JM, Krootila K. Treatment of postoperative keratoplasty astigmatism using femtosecond laser-assisted intrastromal relaxing incisions. J Refract Surg. 2013;29(6):378-382.

14. Nejima R, Terada Y, Mori Y, Ogata M, Minami K, Miyata K. Clinical utility of femtosecond laser-assisted astigmatic keratotomy after cataract surgery. Jpn J Ophthalmol. 2015;59(4):209-215.

15. Yoo A, Yun S, Kim JY, Kim MJ, Tchah H. Femtosecond laser-assisted arcuate keratotomy versus toric IOL implantation for correcting astigmatism. J Refract Surg. 2015;31(9):574-578.

16. Chan TC, Cheng GP, Wang Z, Tham CC, Woo VC, Jhanji V. Vector analysis of corneal astigmatism after combined femtosecond-assisted phacoemulsification and arcuate keratotomy. Am J Ophthalmol. 2015; 160(2):250-255.

17. St Clair RM, Sharma A, Huang D, et al. Development of a nomogram for femtosecond laser astigmatic keratotomy for astigmatism after keratoplasty. J Cataract Refract Surg. 2016;42(4):556-562.

18. Day AC, Lau NM, Stevens JD. Nonpenetrating femtosecond laser intrastromal astigmatic keratotomy in eyes having cataract surgery. $J$ Cataract Refract Surg. 2016;42(1):102-109.

19. Lindstrom RL. The surgical correction of astigmatism: a clinician's perspective. Refract Corneal Surg. 1990;6(6):441-454.

20. Nichamin LD. Astigmatism control. Ophthalmol Clin North Am. 2006; 19(4):485-493.

21. Stein J, Donnenfeld E. Pearls for LRIs with presbyopic IOLs: if left uncorrected, even minimal astigmatism can compromise the visual results of these lenses after cataract surgery. Ophthalmology Management. Epub April 1, 2008.
22. Ouchi M, Kinoshita S. Prospective randomized trial of limbal relaxing incisions combined with microincision cataract surgery. J Refract Surg. 2010;26(8):594-599.

23. Abbott Medical Optics, Inc. LRIcalculator.com. Available from: http://www.lricalculator.com. Accessed February 1, 2016.

24. Koch DD, Ali SF, Weikert MP, Shirayama M, Jenkins R, Wang L. Contribution of posterior corneal astigmatism to total corneal astigmatism. J Cataract Refract Surg. 2012;38(12):2080-2087.

25. Næser K, Savini G, Bregnhøj JF. Estimating total corneal astigmatism from anterior corneal data. Cornea. 2017;36:828-833.

26. Alpins N. Astigmatism analysis by the Alpins Method. J Cataract Refract Surg. 2001;27(1):31-49.

27. Bullimore MA, Spooner G, Sluyterman G, Dishler JG. Correction of low levels of astigmatism. J Cataract Refract Surg. 2015;41(8): 1641-1649.

28. Faktorovich EG, Maloney RK, Price FW Jr. Effect of astigmatic keratotomy on spherical equivalent: results of the astigmatism reduction clinical trial. Am J Ophthalmol. 1999;127(3):260-269.

29. Kumar NL, Kaiserman I, Shehadeh-Mashor R, Sansanayudh W, Ritenour R, Rootman DS. IntraLase-enabled astigmatic keratotomy for post-keratoplasty astigmatism: on-axis vector analysis. Ophthalmology. 2010;117(6):1228-1235.
Clinical Ophthalmology

\section{Publish your work in this journal}

Clinical Ophthalmology is an international, peer-reviewed journal covering all subspecialties within ophthalmology. Key topics include: Optometry; Visual science; Pharmacology and drug therapy in eye diseases; Basic Sciences; Primary and Secondary eye care; Patient Safety and Quality of Care Improvements. This journal is indexed on

\section{Dovepress}

PubMed Central and CAS, and is the official journal of The Society of Clinical Ophthalmology (SCO). The manuscript management system is completely online and includes a very quick and fair peer-review system, which is all easy to use. Visit http://www.dovepress.com/ testimonials.php to read real quotes from published authors. 